\section{Addressing Career Needs of Future Ph.D's}

\section{Sheilah Mann, APSA}

APSA co-sponsored the "National Convocation in Science and Engineering Doctoral Education" hosted by the National Academy of Sciences, the National Academy of Engineering and the Institute of Medicine on June 15, 1996. APSA joined with the national associations for the natural and physical sciences, mathematics, other social sciences, and higher education to support this event entitled "From Discussion to Action: Meeting the Needs of Future Generations of Graduate Scientists and Engineers." This convocation was designed to follow up on a 1995 report from the Committee on Science, Engineering and Public Policy (COSEPUP) entitled, "Reshaping the Graduate Education of Scientists and Engineers" and published by the National Academy Press. The report is a response to decreasing grant support for scientific research and the decline of jobs in academic research institutions.

The convocation featured an array of roundtables, panels and poster sessions. Charles Johnson, chair of the political science department at Texas A\&M, presented a poster on his department's initiative for preparing graduate students to teach undergraduates. His work was also cited in a roundtable on "New Strategies Being Undertaken in the Science and Doctoral Education System."

Presenters encouraged faculty to inform graduate students about alternatives to careers in research and urged faculty to prepare students for professional responsibilities other than research. Faculty and graduate students both urged students to become informed about a wide range of jobs, non-academic as well as academic, teaching and administrative as well as research related. Students expressed concerns about the future of the profession and argued that they lack adequate reference materials and preparation to explore alternative careers. Alternative careers that were discussed include pre-college teaching, public/governmental agencies, professional associations, interest group/advocacy associations, scientific writing/journalism.

\section{References}

"Careers '95: The Future of the Ph.D." 1995. Science. 270 (October 6): 121-149.

"Reshaping the Graduate Education of Scientists and Engineers," 1995. COSEPUP. Washington. National Academy Press.

\section{The National Convocation on Science and Engineering Doctoral Education: A Participant's View}

\section{Charles Johnson, Texas A\&M University}

The National Convocation on Science and Engineering Doctoral Education offered me an opportunity to see a variety of scientific disciplines coping with the prospect of reducing federal funding and increased attention to teaching activities. The Convocation brought together representatives from the natural, biological, medical, and the social sciences to discuss innovations in graduate education in the light of these changes at the national level.

I presented a poster at the session entitled "Department Commitments to Graduate Education" which discussed several initiatives undertaken by our department to strengthen graduate education at the doctoral level. The poster highlighted three features of our $\mathrm{PhD}$ program aimed at producing competitive graduates-(1) intensive mentoring experiences, (2) professional experiences, and (3) exposure to the discipline. Each of these initiatives represented important choices by the department-choices that we support with resources consistent with their priority.

Mentoring Experiences. The $\mathrm{PhD}$ program at Texas A\&M is sufficiently small and the faculty sufficiently large that students work on scholarly projects from the very outset of their graduate study. Key to this approach, which emphasizes individualized mentoring of students, is our graduate assistant assignment process that matches student interests to faculty research projects.
Graduate assistants receive assignments to faculty in their subfield for experiences in research and teaching. Faculty assume a full range of mentoring responsibilities, including the pursuit of jointly authored professional papers and publications, as well as the provision of teaching experiences in the faculty members courses. Significantly, none of the assistants have teaching assistant responsibilities for discussion sessions or individual courses, and they do not assume responsibility for individual classes until they are well advanced in their dissertation research.

Professional Experiences. The graduate program's substantive and methodological seminars are supplemented by experiences intended to broaden professional experiences by the students. Central to these experiences is a formal seminar taught by the Director of Graduate Studies on professional activities. This mandatory one hour seminar taken in the first year of graduate work covers such topics as teaching responsibilities (e.g., approaches to teaching and designing a course), journal publishing, professional meetings and conferences, grant opportunities, and professional ethics. This seminar is supplemented with professional activities pursued as graduate assistants or in collaboration with faculty on scholarly projects.

Exposure to the Discipline. The graduate program makes a special effort to introduce graduate students to scholars and scholarly interests beyond an already large department. Additionally, graduate students receive funding to attend conferences at which they present papers that result from mentoring and professional experiences in the department. We also underwrite a speakers program to bring major scholars to campus for virtually every graduate seminar. These activities underscore commitments to scholarship and broaden the field of view for doctoral students as they prepare to join the discipline.

The departmental thrust of these commitments contrasted sharply with many of the doctoral programs represented at the Convocation. Participants at the meeting often described doctoral programs centered around individual laboratories or small 